\title{
Affected by HIV Stigma: Interpreting results from a population survey of an urban center in Guangxi, China
}

\author{
Laurie Abler ${ }^{1}$, Gail Henderson ${ }^{2}$, Wang Xin ${ }^{3}$, Matthew Avery ${ }^{4}$, Zhang Yingxia ${ }^{5}$, and Pan \\ Suiming 6 \\ ${ }^{1}$ Duke Global Health Institute, Durham, NC, USA \\ ${ }^{2}$ Department of Social Medicine, University of North Carolina-Chapel Hill, NC, USA \\ ${ }^{3}$ Department of Sociology, Shan Dong University, Shan Dong, China \\ ${ }^{4}$ Department of Health Behavior, University of North Carolina-Chapel Hill, NC, USA \\ ${ }^{5}$ Liuzhou CDC, Guangxi, China \\ ${ }^{6}$ Department of Sociology, Renmin University, Beijing, China
}

\begin{abstract}
We aimed to identify factors related to HIV stigma in Liuzhou, Guangxi province, a city in southwest China with high HIV prevalence. We used a multi-stage cluster randomized sample of the general population to survey 852 adults. We conducted ordinal logistic regression analyses to test factors associated with punishment and isolation stigma. Eighteen percent of respondents agreed that people with HIV should be punished, and $40 \%$ agreed that people with HIV should be quarantined. Punishment stigma was associated with age, having three or more sexual partners, and TV watching. Isolation stigma was associated with age, urban residence and a history of STI. HIV transmission knowledge was low, and having correct knowledge attenuated the association with punishment and isolation stigma. Despite programs in China to provide care and treatment for PLHIV, HIV stigma is common in this region. Targeted interventions need to focus on fears related to HIV and PLHIV.
\end{abstract}

\section{Keywords}

China; HIV; stigma; PLHIV

\section{BACKGROUND}

Stigma is defined as the devalued status that society attaches to a condition or attribute ${ }^{(1)}$. Stigma also refers to the socially constructed meanings associated with an attribute (labeled "perceived" or "felt" stigma). Thus, HIV stigma can be thought of as socially-shared knowledge about the devalued status of people living with HIV (PLHIV). Particularly among people not infected with HIV, stigma is manifest via prejudice, rejection, discrediting, stereotyping and discrimination mechanisms aimed toward people perceived to have HIV and the individuals and groups with whom they are associated, which culminate in the effort to distance oneself from PLHIV ${ }^{(2-5)}$. Although stigma toward PLHIV may be held by individuals, collectively, stigma is developed through a shared social process of labeling, stereotyping, lowering status, and discriminating ${ }^{(6)}$ against PLHIV, and this process occurs 
within the social power structure that negatively associates HIV infection with gender, class, race, and sexuality-based inequalities $(7,8)$.

UNAIDS identifies HIV stigma as one of the key social factors driving the spread of HIV and hindering the treatment of PLHIV ${ }^{(9)}$. The negative impact of stigma on HIV prevention and treatment for PLHIV is well known ${ }^{(7,10)}$ and serves to isolate PLHIV socially and physically ${ }^{(11)}$. The effect of stigma on HIV prevention and treatment is particularly salient in China, where in 2011 it was estimated that $57 \%$ of those with HIV were unaware of their serostatus even though efforts to improve testing rates are a national priority ${ }^{(12)}$. Of those who do know their status, PLHIV who perceive and encounter stigmatizing attitudes avoid treatment services ${ }^{(13)}$ and hide their serostatus from sexual partners and medical staff ${ }^{(14-16)}$, both because they fear discrimination at the hands of health staff and because they fear the social consequences for themselves and their families if their status becomes known or suspected ${ }^{(17)}$. Similarly, HIV-related stigma may act as a barrier to participation in HIV prevention programming, even among individuals who are not HIV positive ${ }^{(18,19)}$.

Numerous studies have documented the general public's negative attitudes toward PLHIV in both rural and urban areas of China ${ }^{(20-23)}$. Commonly reported stigmatizing attitudes in China include, for example, that it is not safe for someone with HIV to take care of other people's children, that PLHIV persons should be isolated, that PLHIV bring shame to their families, and that seropositive persons deserve to be punished ${ }^{(21,22,24)}$. These beliefs persist even among (presumably better informed) Chinese health care providers, who exhibit generally low levels of support for PLHIV (25-27). Stigma contributes to these attitudes, as some providers reported feeling stigma and shame as a result of being associated HIV patients ${ }^{26)}$, although providers with increased empathy had reduced avoidance of PLHIV, which improved the quality of their care ${ }^{(28)}$.

According to Herek ${ }^{(29)}$, there are two main components of stigma: 1) the instrumental stigma which results from fear of contracting HIV; and 2) the symbolic stigma which results from the socially derived values that form the moral judgment against behaviors and people associated with HIV infection. With regards to instrumental stigma, most of the Chinese stigma studies show that accurate understanding of the main routes of HIV transmission is generally widespread; however misconceptions persist regarding the rarity of casual transmission and people use these beliefs as reasons to fear PLHIV ${ }^{(24)}$. Many people tend to overestimate the contagiousness of HIV ${ }^{(17)}$, and this concern about HIV transmission translates into avoiding interactions with PLHIV (30). Importantly, individuals who believe that casual contact can transmit HIV are much more likely to hold stigmatizing attitudes $(20,23)$. For symbolic stigma, evidence that individuals blame PLHIV for their infection continues, primarily as a moral judgment against the behaviors associated HIV infection. Some studies in China have found that blame and rejection of PLHIV is distinct from any fears of infection, and this stigma results from social and cultural values ${ }^{(31,32)}$. Chinese PLHIV who were infected through blood plasma donation are not "blamed" for having acted in a risky way that led to their infection; instead, fear of infection from, but not judgment of, the PLHIV acts as the main driver of stigma ${ }^{(11)}$.

Efforts to assess social- and individual-level HIV stigma, both perceived by PLHIV and enacted by HIV negative individuals, have proliferated in recent years (see ${ }^{(7)}$ for a systematic review of this literature). We undertook this study to explore the beliefs and attitudes of the general population in Liuzhou in order to reveal the stigmatizing perceptions of PLHIV and the HIV epidemic. Liuzhou is a city located in Guangxi province in southwest China, and given its proximity to the drug trafficking routes in Vietnam and Southeast Asia, it was among the first regions to experience the HIV epidemic. The first HIV case was identified in Liuzhou in 1996. Between 1996 and 2007, injection drug use 
(IDU) accounted for the majority of transmission events. By 2012, the cumulative number of HIV cases in Liuzhou was 11,323 (unpublished data from China's information system for disease control and prevention). While drug use continues to be a significant problem in Liuzhou, heterosexual transmission is now the main route of infection. The Liuzhou CDC conducts targeted surveillance of high-risk groups each year. In 2008, their surveillance data reported HIV prevalence as $15.6 \%$ among IDU, $2.9 \%$ among MSM, and $0.5 \%$ among female sex workers ${ }^{(33)}$. In the following year, their surveillance data reported $21 \%$ prevalence among IDU ${ }^{(34)}$ and $2.3 \%$ among female sex workers ${ }^{(35)}$. By 2012, heterosexual contact accounted for the vast majority (89\%) of new infections in Liuzhou, compared to injection drug use (6\%) and men who have sex with men (1\%) (unpublished data from China's information system for disease control and prevention). In response, Liuzhou has established multi-sectorial working groups to address prevention, education, and treatment interventions for high-risk groups, funded in part by national and international agencies and grants.

As China continues to commit to its "Four Frees and One Care" program to identify PLHIV and provide comprehensive care and treatment services ${ }^{(12,36)}$, it is vital to characterize HIV stigma in locations like Liuzhou, which has the potential to compromise the impact of these programs. This is particularly important as the risk of HIV infection becomes more prevalent among the general population where otherwise little is known about how people not infected with HIV perceive and react to PLHIV. We report on stigma findings from a population survey conducted in Luizhou. The purpose of the study is to gain greater understanding of factors associated with the stigma attitudes and beliefs held by Liuzhou residents in order to develop better targets for stigma reduction efforts. This research specifically addresses two extreme stigmatizing beliefs in the Liuzhou general population related to symbolic and instrumental stigma and explores the factors associated with greater stigmatizing attitudes.

\section{METHODS}

\section{Study Design}

The work presented in this manuscript occurred as a sub-study of the R24 Partnership for Social Science Research on HIV/STI in China. We conducted this secondary analysis using survey data collected in urban Liuzhou in June and July 2008. The overall purpose of the survey was to provide background information for other HIV-related studies sponsored by the R24 collaboration, which focused on Liuzhou's high HIV risk populations. The region is hard-hit by the HIV epidemic and was selected as a demonstration site for the collaborative R24 research and training grant between the University of North Carolina-Chapel Hill, Renmin University in Beijing, and the National Center for STD Control in Nanjing, China.

The 2008 Liuzhou sampling design and survey were adapted from the 2006 Chinese Health and Family Life Survey (CHFLS), a nationally representative survey of Chinese adults focused on sexual partnerships, behaviors, and attitudes, which are linked to STI and HIV risk ${ }^{(37)}$. The primary and secondary sampling units were selected with probability proportional to size. Eight urban neighborhoods (jiedao) in Liuzhou were randomly selected as the primary sampling unit, followed by random selection of three residence committees (juweihui) in each of the eight neighborhoods as the secondary sampling unit, amounting to 24 residence committees. We randomly selected households using the household registration lists in each residence committee. Then, individual respondents $(\mathrm{n}=1209)$ who appeared on the residence committee list as permanent residents or as migrants registered as temporary residents, and who were at least 18 years old, were invited to participate. The audio computer assisted self-interview (ACASI) survey was completed by 852 respondents $(70.5 \%$ 
response rate) ages $18-61$ at a private venue to preserve the confidentiality of the respondents. The Renmin University of China IRB approved the study.

\section{Study Setting}

Liuzhou is an industrial city that serves as a transportation hub for southwest China. The city has several industrial and high-tech development zones and is a major tourist center. While the survey was conducted in Liuzhou's four urban districts, the city also includes six surrounding rural counties. The total urban population is approximately 1.3 million, about 300,000 of whom are migrants.

\section{Measures}

Main outcome measures-With permission of Lee and colleagues ${ }^{(22)}$, we used two stigma questions from their study conducted with market stall employees and owners in an Eastern coastal city in China. The two items were answered on a 5-point Likert scale ( $1=$ strongly disagree, $2=$ disagree, $3=$ not sure, $4=$ agree, $5=$ strongly agree $)^{1}: 1$ ) people with HIV must have done something bad and should be punished, and 2) people with HIV should be quarantined. Throughout the analysis, these outcomes are referred to as "punishment" and "isolation" stigma, respectively. We chose these items because they capture severe aspects of stigma, which would most likely impede HIV testing and disclosure of serostatus. Further, these items have the potential to represent two key components of the stigma construct ${ }^{(29)}: 1$ ) the punishment item representing symbolic stigma - the expression of moral judgment and blame against the behaviors associated with HIV infection (e.g., promiscuity, homosexuality, drugs, and commercial sex); and 2) the isolation item representing instrumental stigma - the expression of fear of casual HIV infection.

Protective and Risk Factors-Based on the literature, we identified factors potentially related to HIV stigma, including demographic and socioeconomic characteristics, HIV knowledge and risk behaviors, and media measures. The following variables were tested as factors associated with stigmatizing attitudes: number of lifetime sexual partners $(0,1,2,3$ or more), tested for HIV (yes, no), number of days of reading the newspaper in a week, number of hours of TV watching in a day, and internet use (never use, sometimes use, and often use). We created a measure of HIV transmission knowledge by asking respondents if sharing utensils and sneezing can transmit HIV; respondents were categorized as those who believe that both sneezing and sharing utensils cannot transmit HIV (know all), those who believe that either sneezing or sharing utensils can transmit HIV (know some), and those who believe that both sneezing and sharing utensils can transmit HIV (know none). A history of a previous sexually transmitted infection (yes, no) was determined for respondents who reported ever having syphilis, gonorrhea, chlamydia, herpes, genital warts, or trichomoniasis. We hypothesized that more HIV knowledge and media use would be protective factors associated with less stigma, while indicators of greater sexual risk behavior, such as more sexual partners or history of an STI diagnosis, would be risk factors associated with more stigma. We included the socio-demographic variables gender, age, location of permanent household registration (urban, rural), education level (less than high school, high school graduate, more than high school), employment status (full-time worker,

${ }^{1}$ Chinese translation of the HIV stigma questions.

Punishment Stigma:

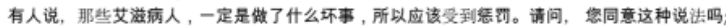

Isolation Stigma:

艾滋病人应该被隔离开来。请问，您同意这种说法吗 
not employed, retired, temporary worker), has children (yes, no), and has a current partner (yes, no) as control variables.

\section{Analysis}

First, we calculated descriptive statistics of the sample by gender. We conducted simple ordinal logistic re gression analysis to identify bivariate correlations of factors associated with punishment and isolation stigma. Adjusted odds ratios (AORs) and their 95\% confidence intervals (CIs) were calculated; variables in the multivariate ordinal logistic regression model included those associated with stigma in the bivariate analysis or hypothesized a priori. All regression analyses controlled for clustering and were weighted to be representative of the age and gender distribution of Liuzhou ${ }^{(38)}$. The analyses were performed using SAS 9.2 (SAS Institute Inc.) and findings were presented using unweighted counts and weighted percentages.

\section{RESULTS}

Characteristics of the population sample are summarized in Table I, by gender, to document differences between females and males. The weighted sample includes slightly more males (52\%) than females. The average age was 38 years. Over twenty percent of the respondents for this survey, which was conducted in urban districts, held a rural permanent household registration, which implies that they were rural-to-urban migrants, and on the residence committee list as "temporary residents". More than a third (38\%) of the sample had not completed high school, while $39 \%$ had graduated from high school and $24 \%$ had continued their studies beyond high school. Forty-six percent of respondents knew that neither sneezing nor sharing utensils can transmit HIV, 20\% thought either sneezing or sharing utensils can transmit HIV, and 34\% thought that both can transmit HIV. All but $7 \%$ of the sample had at least one sexual partner in their lifetime. Twelve percent reported a history of an STI and 8\% had been tested for HIV. Eighty-four percent reported having a current partner and 33\% did not have children. In general, media use was high. The median number of days reading the newspaper in a week was 4.0, the median number of hours of TV watched in a day was 2.9 , and $39 \%$ reported using the internet often. There were few significant differences between females and males. Males (55\%) were more likely to have full-time employment than females (39\%), while females were more likely to be retired (16\% versus $7 \%$ ) or not employed (10\% versus $5 \%)$. Females had fewer lifetime sexual partners than males. Males had greater internet use than females.

Survey respondents held higher isolation stigmatizing attitudes than punishment stigmatizing attitudes (Table II). Forty percent of the sample reported high or very high isolation stigma, while $18 \%$ of the sample reported high or very high punishment stigma. Punishment stigma was positively correlated with isolation stigma $(\mathrm{r}=0.46, \mathrm{p}<.01)$.

We conducted simple ordinal logistic regression analyses to determine the HIV risk factors and protective behaviors associated with HIV punishment and isolation stigma. In the bivariate analysis, greater age, less education, non-full time work, less HIV transmission knowledge, more lifetime sexual partners, having a history of STI, less newspaper reading and TV watching, and less internet use were significantly associated with an increased odds of punishment stigma (Table III). Older age, rural residence, less education, temporary employment, less HIV transmission knowledge, having a history of STI, never testing for HIV, less newspaper reading, and less internet use was significantly associated with increased odds of isolation stigma (Table IV).

The results of multivariate ordinal logistic regression models testing the associations with the punishment (Table III) and isolation stigma (Table IV) outcomes were controlled for 
age, gender, education, urban registration, and employment. When fit into the multivariate model, many of the factors that were significant in the simple model were no longer significant when controlling for other predictors. Overall, having the knowledge to reject HIV transmission myths served as the adjusted covariate with the strongest and most consistent negative association with both punishment and isolation stigma. The effect of HIV transmission knowledge was incremental; the odds ratio of punishment stigma were attenuated to $0.67(95 \% \mathrm{CI}=0.46-0.96)$ for those with some and $0.52(95 \% \mathrm{CI}=0.38-0.71)$ for those with all HIV knowledge, and the odds ratio of isolation stigma were attenuated to $0.63(95 \% \mathrm{CI}=0.44-0.90)$ for respondents with some and $0.38(95 \% \mathrm{CI}=0.28-0.51)$ for respondents with all HIV knowledge. Older age increased the odds of punishment (AOR $1.03 ; 95 \% \mathrm{CI}=1.01-1.04)$ and isolation stigma ( $\mathrm{AOR} 1.02 ; 95 \% \mathrm{CI}=1.01-104)$.

A higher number of lifetime sexual partners was significantly associated with punishment stigma; for respondents with three or more sexual partners in their lifetime, the odds of very high punishment stigma are 3.24 times $(95 \% \mathrm{CI}=1.41-7.43)$ as likely as the odds of responding to a lesser category of punishment stigma. Full-time work status was protective for punishment stigma; those who did not work (AOR 2.34; 95\% CI = 1.33-4.12) and those who worked on temporary contracts (AOR $1.74 ; 95 \% \mathrm{CI}=1.28-2.38$ ) were more likely to endorse higher punishment stigma. A history of STI was a risk for greater isolation stigma (AOR $1.65 ; 95 \% \mathrm{CI}=1.11-2.43$ ) but not for punishment stigma (AOR $1.48 ; 95 \% \mathrm{CI}=$ 0.99-2.20). Notably, having a history of testing for HIV was not significantly associated with punishment or isolation stigma in the multivariate models.

\section{DISCUSSION}

The levels of endorsement for the punishment and isolation stigma items are quite high in this representative sample of the general population of Liuzhou, with $18 \%$ of the general population sample supporting the belief that PLHIV deserved to be punished for their infection and $40 \%$ agreeing that PLHIV should be isolated from others through quarantine.

PLHIV living in Liuzhou feel the effects of both the symbolic and instrumental stigmatizing attitudes, which have a substantial impact on their lives. For example, stigma can lead to the loss of social and emotional support of their families, friends and significant others who are afraid of HIV infection and associating with someone who is living with HIV; to the loss of employment despite the desire to work, which affects their income and in turn leads to the inability to afford their treatment; and to self-isolation and negative mental health consequences ${ }^{(24)}$. The levels of stigma we found were similar to general population samples in other settings in China. For example, in their 2002 article, Derlega and colleagues (39) found that $53 \%$ of a sample of the general population in a province in Southwestern China endorsed isolation stigma.

The higher prevalence of isolation stigma than punishment stigma suggests that more of the stigma against PLHIV is driven by fear of infection, rather than the moral judgment reflected by the punishment item. Further, although the two stigma items are correlated, the associated risk behaviors do not entirely overlap, so there are likely slight differences in the processes that drive how these stigmatizing attitudes are held. While a history of STI was associated with isolation stigma, having more sexual partners was associated with punishment stigma. However, what is not clear is the nature of the relationship between different risk behaviors and punishment and isolation stigma. Because of the social processes that drive stigma, it is likely that navigating sexual relationships and dealing with the potential consequences of risk behaviors associated with contracting HIV influence the stigmatizing attitudes toward PLHIV. Respondents with a previous STI may report more isolation stigma as way to label and distance themselves from "others" who have the potential to put them at risk for another STI or HIV. The endorsement of punishment stigma 
could reflect distancing from the stigma targeted inwardly on themselves, i.e., internalized stigma, and the self-blame that they may feel as a result of having multiple sexual partners. Regardless of the mechanism, risk behaviors in this setting are associated with greater stigmatizing attitudes. This confirms other findings that risk behavior is associated with high stigma in China ${ }^{(14,20)}$. In a study among market vendors in eastern China that used the same stigma items ${ }^{(22)}$, individuals who had more lifetime sexual partners were more likely to believe that PLHIV should be punished for their infection. Not all evidence points in the same direction, however. Another study found greater HIV risk behaviors among female migrants in Shanghai, such as premarital sex and multiple sexual partners, but less stigma measured through prejudicial attitudes ${ }^{(40)}$. The equivocation in the evidence describing the associations between risk behavior and stigma lends further strength to the argument that stigma is developed through a complex social process informed by the power structure that exists in a particular social and cultural context ${ }^{(7,8)}$.

The majority of participants were misinformed about how HIV is spread, believing that HIV is readily transmitted through casual contact. Those with the most knowledge about HIV transmission were at decreased risk of both isolation and punishment stigmatizing attitudes, and even participants with some HIV knowledge held less stigma than those with no HIV knowledge. This finding underscores the link that fear of infection has in driving the stigma process, assuming that our indicators of knowledge signifies a better understanding of the mechanisms of HIV transmission. However, we found that HIV knowledge is not only related with the isolation item, potentially representing instrumental stigma or the fear of infection, but also with the punishment item, potentially representing the symbolic stigma or moral judgment of people affected by HIV. Further research is necessary to understand the underlying social process that is driving the relationship between knowledge and different components of stigma.

While the relationship between HIV stigma and transmission knowledge is welldocumented ${ }^{(20,40)}$, interventions to improve individual-level knowledge alone have not been effective at decreasing HIV stigma ${ }^{(41)}$. More recent efficacious stigma interventions utilize a multi-faceted approach that broaden HIV knowledge along with other targets, such as providing stigma reduction messages to health care providers using popular opinion leaders ${ }^{(42)}$ or distributing community-level HIV and prevention information to market workers to change their social norms ${ }^{(43)}$. Further, exposure to media messaging may be one mechanism to decrease misconceptions about how HIV is spread, thereby reducing stigma in the general population. Although marginally significant in our study findings, media use, like the internet, TV, and newspaper, seems to have a slight protective effect on HIV stigma. We did not measure the content of the media messages to which people were exposed. Certainly, this information would be necessary to determine how the media and type of messages shape stigmatizing attitudes in order to tailor the contents better. Media interventions for HIV stigma may prove effective at simultaneously improving HIV knowledge and changing the social norms necessary for communities to support reduced $\operatorname{stigma~}^{(43,44)}$.

Our study has limitations. A cross-sectional analysis cannot support causal inferences regarding the nature of the relationship between risk behaviors and isolation and punishment stigma. Asking about more, different types of stigma attitudes toward PLHIV would have captured additional complexity of how stigma is manifest in the study population. Isolation and punishment items do not measure other aspects of the stigmatizing process, such as labeling, stereotyping, and distancing. And, while we argue that the punishment and isolation items capture the symbolic and instrumental stigma constructs, we cannot be sure that is the case. As the HIV epidemic matures and HIV knowledge increases, people may have become more aware of the problems of expressing overt forms of HIV stigma, creating 
a social desirability bias resulting in the underreporting of stigmatizing beliefs. It is difficult to know how much of this affected our survey results. Like others calling for improved stigma measurement ${ }^{(45,46)}$, we recommend developing valid and reliable measures in the Chinese context to capture the nuances of these mutable stigmatizing attitudes in general population samples as the HIV epidemic evolves over time. Finally, there were factors that we consider important, but that we were not able to measure, such as the sources of participants' HIV-related knowledge, the contents of the media to which participants were exposed, and the potential associations between different types of media-messaging and HIV-related knowledge.

Despite these limitations, this study provides evidence that high levels of stigma are held within the general population of Liuzhou, in a sample that is generalizable to the permanent and temporary residents in Liuzhou who are recorded on the residence committee list. The effects of these stigmatizing attitudes have palpable consequences for the physical and mental health of PLHIV living in Liuzhou ${ }^{(24,47)}$. Failure to address this stigma in the general population has the potential to undermine China's commitment to reducing new infections and HIV-related mortality ${ }^{(48)}$. In developing interventions to reduce stigma among the residents of Liuzhou, it is critical that we not only intervene on the social aspects of stigma that drive moralization against PLHIV, but we must also continue to address how fear of casual contact fuels stigma.

\section{Acknowledgments}

The research was supported by the US NIH R24 grant (HD056670) for Partnership for Social Science Research on HIV/AIDS in China and by the UNC Center for AIDS Research (CFAR), an NIH funded program (P30 AI50410). The authors would like to thank Malena Rousseau and Catherine Bolland Emrick for their assistance with manuscript revision.

\section{References}

1. Goffman, E. Stigma: Notes on the Management of Spoiled Identity. New York and London: Simon \& Schuster; 1963.

2. Deacon, H.; Stephney, I.; Prosalendis, S. Understanding HIV/AIDS Stigma: A Theoretical and Methodological Analysis. HSRC Press; 2005. distributed worldwide, except Africa, by Worldwide Publishers Group

3. Herek GM, Capitanio JP, Widaman KF. HIV-related stigma and knowledge in the United States: prevalence and trends, 1991-1999. Am J Public Health. Mar; 2002 92(3):371-377. [PubMed: 11867313]

4. Steward W, Herek G, Ramakrishna J, et al. HIV-related stigma: adapting a theoretical framework for use in India. Soc Sci Med. 2008; 67(8):1225-1235. [PubMed: 18599171]

5. Earnshaw VA, Chaudoir SR. From conceptualizing to measuring HIV stigma: a review of HIV stigma mechanism measures. AIDS Behav. 2009; 13(6):1160-1177. [PubMed: 19636699]

6. Link BG, Phelan JC. Conceptualizing Stigma. Ann Rev Sociol. 2001; 27:363-385.

7. Mahajan A, Sayles J, Patel V, et al. Stigma in the HIV/AIDS epidemic: a review of the literature and recommendations for the way forward. AIDS. 2008; 22:S67. [PubMed: 18641472]

8. Parker R, Aggleton P. HIV and AIDS-related stigma and discrimination: a conceptual framework and implications for action. Soc Sci Med. Jul; 2003 57(1):13-24. [PubMed: 12753813]

9. UNAIDS. Global report: UNAIDS report on the global AIDS epidemic. Geneva: UNAIDS; 2010.

10. Obermeyer CM, Osborn M. The Utilization of Testing and Counseling for HIV: A Review of the Social and Behavioral Evidence. Am J Public Health. 2007; 97(10):1762. [PubMed: 17761565]

11. Cao X, Sullivan SG, Xu J, Wu Z. Understanding HIV-related stigma and discrimination in a "blameless" population. AIDS Educ Prev. 2006; 18(6):518-528. [PubMed: 17166078]

12. Ministry of Health People's Republic of China. . 2012 China AIDS Response Progress Report. Beijing: 2012. 
13. Lieber E, Li L, Wu Z, Rotheram-Borus MJ, Guan J. HIV/STD stigmatization fears as healthseeking barriers in China. AIDS Behav. Sep; 2006 10(5):463-471. [PubMed: 16374668]

14. Liu H, Hu Z, Li X, Stanton B, Naar-King S, Yang H. Understanding interrelationships among HIV-related stigma, concern about HIV infection, and intent to disclose HIV serostatus: a pretestposttest study in a rural area of eastern China. AIDS Patient Care STDS. 2006; 20(2):133. [PubMed: 16475894]

15. Wong V, Wong L. Management of stigma and disclosure of HIV/AIDS status in healthcare settings. J Health Organ Manag. 2006; 20(2):95-114. [PubMed: 16869347]

16. Yang H, Li X, Stanton B, Fang X, Lin D, Naar-King S. HIV-related knowledge, stigma, and willingness to disclose: A mediation analysis. AIDS Care. 2006; 18(7):717-724. [PubMed: 16971280]

17. Zhou Y. "If you get AIDS You have to endure it alone": Understanding the social constructions of HIV/AIDS in China. Soc Sci Med. 2007; 65(2):284-295. [PubMed: 17459546]

18. Deng R, Li J, Sringernyuang L, Zhang K. Drug abuse, HIV/AIDS and stigmatisation in a Dai community in Yunnan, China. Soc Sci Med. 2007; 64(8):1560-1571. [PubMed: 17257727]

19. Yang H, Li X, Stanton B, et al. Willingness to participate in HIV/STD prevention activities among Chinese rural-to-urban migrants. AIDS Educ Prev. 2004; 16(6):557. [PubMed: 15585431]

20. Chen J, Choe MK, Chen S, Zhang S. Community environment and HIV/AIDS-related stigma in China. AIDS Educ Prev. 2005; 17(1):1-11. [PubMed: 15843106]

21. Derlega VJ, Yang X, Luo H. Misconceptions about HIV transmission, stigma and willingness to take sexual risks in southwestern China. Int J STD AIDS. Jun; 2006 17(6):406-409. [PubMed: 16734964]

22. Lee M, Wu Z, Rotheram-Borus M, Detels R, Guan J, Li L. HIV-related stigma among market workers in China. Health Psychol. 2005; 24(4):435-438. [PubMed: 16045380]

23. Qian H, Wang N, Dong S, et al. Association of misconceptions about HIV transmission and discriminatory attitudes in rural China. AIDS Care. 2007; 19(10):1283-1287. [PubMed: 18071972]

24. Hua J, Emrick CB, Golan CE, et al. How People Living with HIV in Liuzhou, China, Experience Stigma. AIDS Behav. 2012 (in preparation).

25. Li L, Wu Z, Zhao Y, Lin C, Detels R, Wu S. Using case vignettes to measure HIV-related stigma among health professionals in China. Int J Epidemiol. 2006

26. Li L, Wu Z, Wu S, Zhaoc Y, Jia M, Yan Z. HIV-related stigma in health care settings: a survey of service providers in China. AIDS Patient Care STDS. 2007; 21(10):753-762. [PubMed: 17949274]

27. Webber G. Chinese health care providers' attitudes about HIV: A review. AIDS Care. 2007; 19(5): 685-691. [PubMed: 17505931]

28. Lin C, Li L, Wan D, Wu Z, Yan Z. Empathy and avoidance in treating patients living with HIV/ AIDS (PLWHA) among service providers in China. AIDS Care. 2012; 24(11):1341-1348. [PubMed: 22292939]

29. Herek GM, Capitanio JP. Symbolic prejudice or fear of infection? A functional analysis of AIDSrelated stigma among heterosexual adults. Basic Appl Soc Psych. 1998; 20(3):230-241.

30. Burki TK. Discrimination against people with HIV persists in China. Lancet. 2011; 377(9762): 286-287. [PubMed: 21322842]

31. Hong Y, Li X, Stanton B, et al. Expressions of HIV-related stigma among rural-to-urban migrants in China. AIDS Patient Care STDS. 2008; 22(10):823-831. [PubMed: 18847389]

32. Zhou, YR. Stigma, Discrimination and Living with HIV/AIDS. Springer; 2013. Morality, Discrimination, and Silence: Understanding HIV Stigma in the Sociocultural Context of China; $p$. 117-132.

33. Liuzhou, CDC. [Accessed 25 November, 2009] AIDS is Spreading to the General Population in Liuzhou, and the Epidemic Situation is Very Serious. 2009. http://www.chinadaily.com.cn/dfpd/ 2009-11/25/content_9156604.htm

34. Tan Y, Wei Q, Chen L, et al. Molecular epidemiology of HCV monoinfection and HIV/HCV coinfection in injection drug users in Liuzhou, Southern China. PLoS One. 2008; 3(10):e3608. [PubMed: 18974888] 
35. Lu F, Jia Y, Sun X, et al. Prevalence of HIV infection and predictors for syphilis infection among female sex workers in southern China. Southeast Asian J Trop Med Public Health. 2009; 40(2): 263-272. [PubMed: 19323011]

36. Cui Y, Liau A, Wu Z. An overview of the history of epidemic of and response to HIV/AIDS in China: achievements and challenges. Chin Med J (Engl). 2009; 122(19):2251-2257. [PubMed: 20079122]

37. Pan, S.; Huang, Y.; Wang, D. Social Research on Methods: Quantitative and Qualitative Sociological Studies in Chinese Contexts (Chinese Edition). Beijing, China: Renmin University Press; 2011.

38. Liuzhou Municipal Bureau of Statistics. Liuzhou Economic Statistical Yearbook — 2009. Beijing, China: China Statistical Press; 2010.

39. Derlega VJ, Winstead B, Greene K, Servoich J, Elwood WN. Perceived HIV-related Stigma and HIV Disclosure to Relationship Partners after Finding Out about the Seropositive Diagnosis. J Health Psychol. 2002; 7(4):415. [PubMed: 22112752]

40. Cao H, He N, Jiang Q, et al. Stigma against HIV-infected persons among migrant women living in Shanghai, China. AIDS Educ Prev. 2010; 22(5):445-454. [PubMed: 20973664]

41. Brown L, Macintyre K, Trujillo L. Interventions to reduce HIV/AIDS stigma: what have we learned? AIDS Educ Prev. Feb; 2003 15(1):49-69. [PubMed: 12627743]

42. Li L, Wu Z, Liang L-J, et al. Reducing HIV-Related Stigma in Health Care Settings: A Randomized Controlled Trial in China. Am J Public Health. 2013; 103(2):286-292. [PubMed: 23237175]

43. Li L, Liang LJ, Lin C, Wu Z, Rotheram-Borus MJ. HIV prevention intervention to reduce HIVrelated stigma: evidence from China. AIDS. 2010; 24(1):115. [PubMed: 19926963]

44. State Council AIDS Working Committee Office and UN Theme Group on AIDS in China. A joint assessment of HIV/AIDS prevention, treatment and care in China. 2007.

45. Nyblade L. Measuring HIV stigma: Existing knowledge and gaps. Psychol Health Med. 2006; 11(3):335-345. [PubMed: 17130069]

46. Sengupta S, Banks B, Jonas D, Miles M, Smith G. HIV interventions to reduce HIV/AIDS stigma: A systematic review. AIDS Behav. 2011:1-13. [PubMed: 20683650]

47. Zhang Y, Li M, Zhang N, Bu J. Coping Strategies for HIV-Related Stigma in Liuzhou, China. AIDS Behav. forthcoming.

48. Qiu J. Stigma of HIV imperils hard-won strides in saving lives. Science. 2011; 332(6035):12531254. [PubMed: 21659579] 


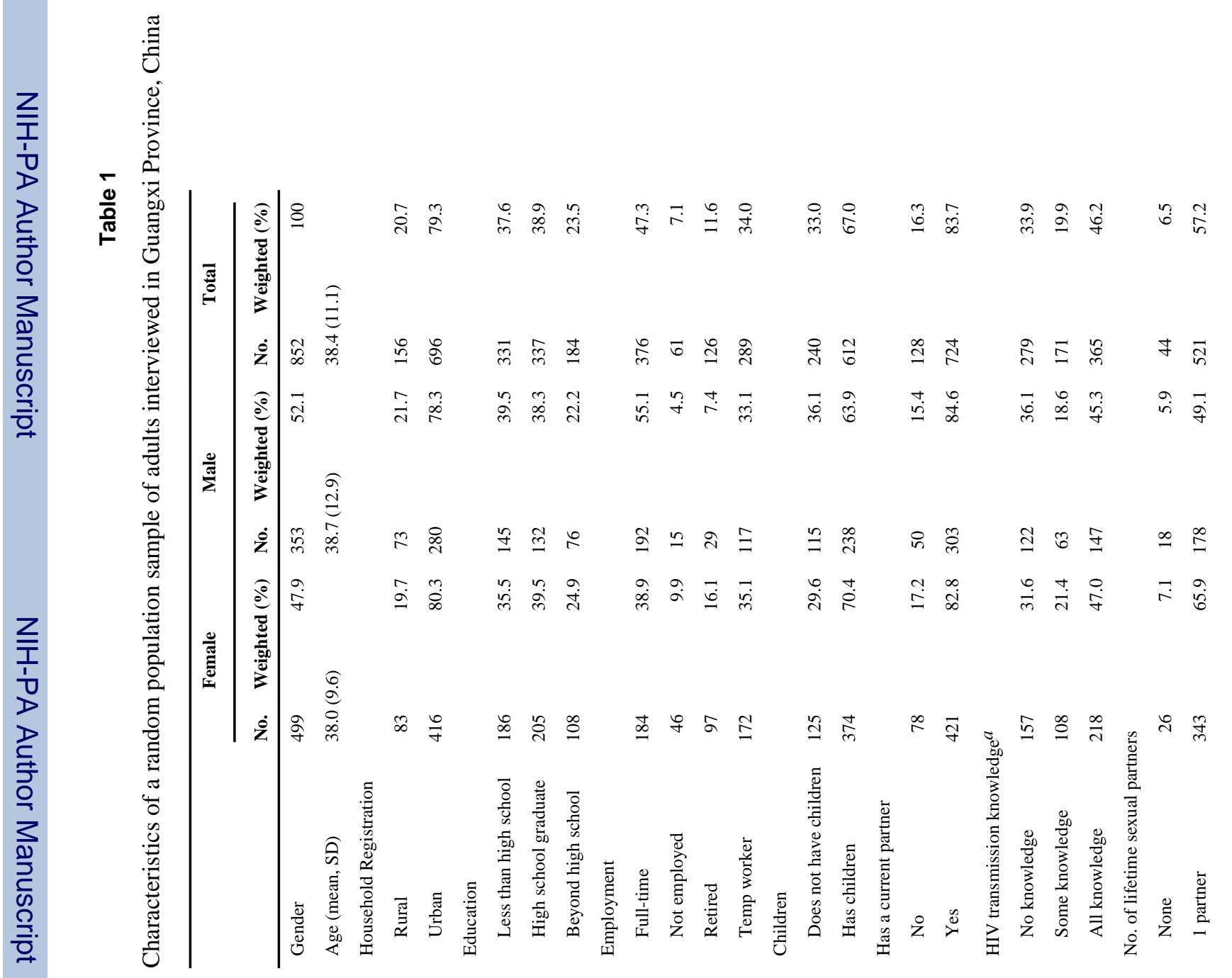




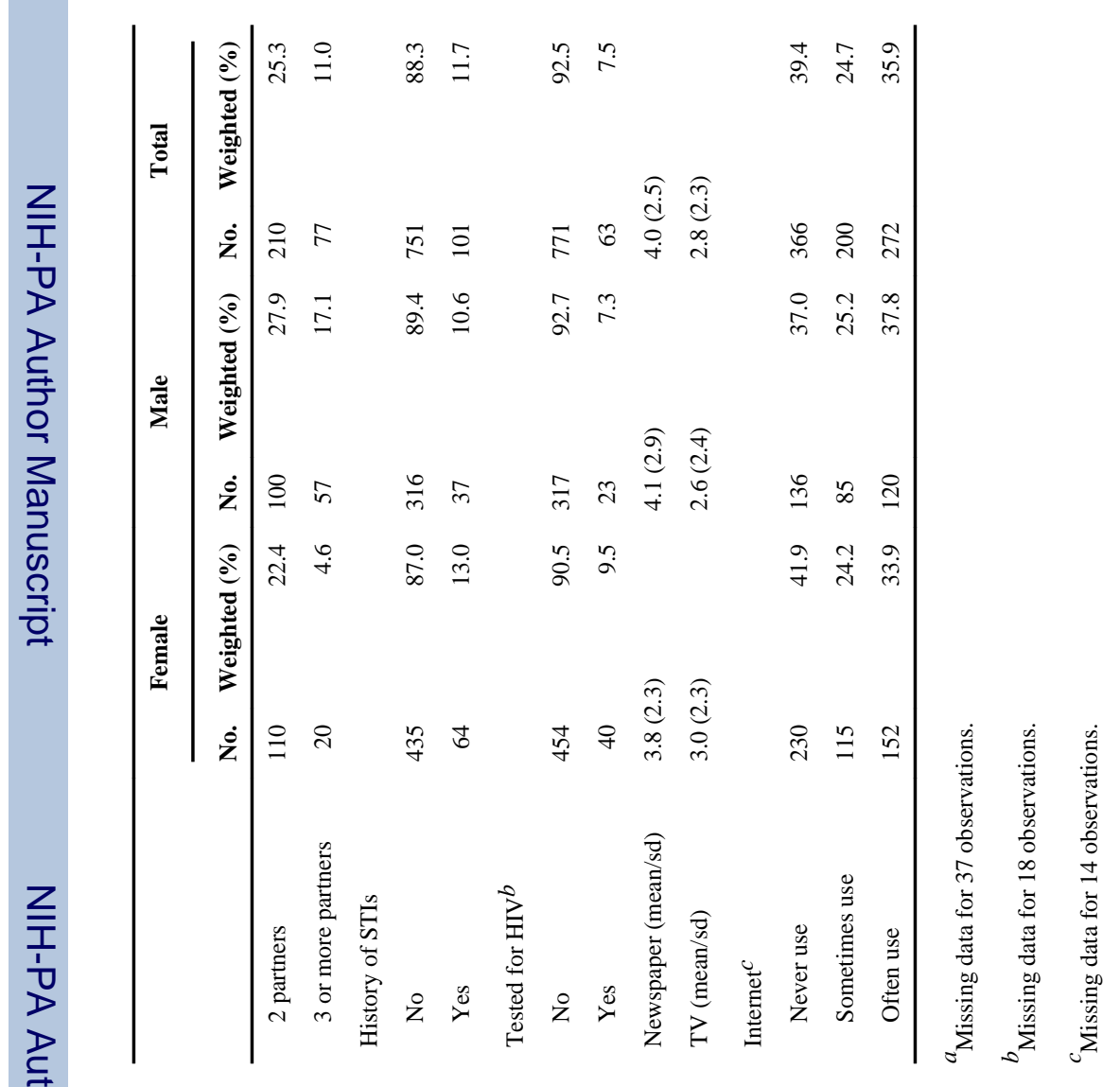




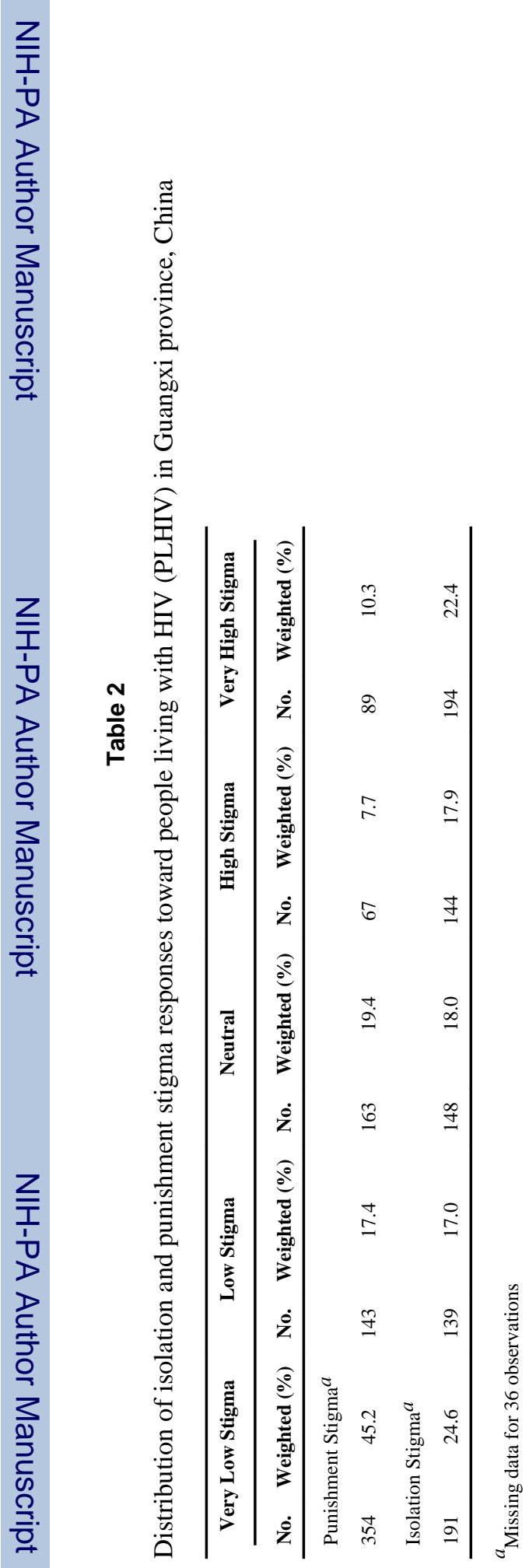


Table 3

Bivariate and multivariate ordinal logistic regression models predicting punishment stigma among adults ages 18-61 in Guangxi Province, China

\begin{tabular}{|c|c|c|c|c|}
\hline & \multicolumn{2}{|c|}{$\underline{\text { Bivariate Analyses }}$} & \multicolumn{2}{|c|}{$\underline{\text { Multivariate Analyses }}$} \\
\hline & OR & $95 \% \mathrm{CI}$ & $\mathbf{A O R}^{\boldsymbol{X}}$ & $95 \% \mathrm{CI}$ \\
\hline \multicolumn{5}{|l|}{ Gender } \\
\hline Female & 1.0 & & 1.0 & \\
\hline Male & 0.88 & $0.68-1.13$ & 0.87 & $0.66-1.15$ \\
\hline Age & 1.03 & $1.02-1.04$ & 1.03 & $1.01,1.04$ \\
\hline \multicolumn{5}{|l|}{ Household Registration } \\
\hline Rural & 1.0 & & 1.0 & \\
\hline Urban & 0.74 & $0.55,1.01$ & 0.78 & $0.53,1.14$ \\
\hline \multicolumn{5}{|l|}{ Education } \\
\hline Less than high school & 1.0 & & 1.0 & \\
\hline High school graduate & 0.59 & $0.44,0.79$ & 0.86 & $0.62,1.20$ \\
\hline Beyond high school & 0.47 & $0.34,0.67$ & 1.03 & $0.66,1.60$ \\
\hline \multicolumn{5}{|l|}{ Employment } \\
\hline Full-time & 1.0 & & 1.0 & \\
\hline Not employed & 1.74 & $1.03,2.94$ & 2.34 & $1.33,4.12$ \\
\hline Retired & 1.90 & $1.27,2.85$ & 1.16 & $0.72,1.87$ \\
\hline Temporary worker & 2.06 & $1.55,2.75$ & 1.74 & $1.28,2.38$ \\
\hline \multicolumn{5}{|l|}{ Transmission knowledge } \\
\hline No knowledge & 1.0 & & 1.0 & \\
\hline Some knowledge & 0.61 & $0.43,0.86$ & 0.67 & $0.46,0.96$ \\
\hline All knowledge & 0.42 & $0.32,0.57$ & 0.52 & $0.38,0.71$ \\
\hline \multicolumn{5}{|c|}{ Number of lifetime sexual partners } \\
\hline None & 1.0 & & 1.0 & \\
\hline 1 partner & 2.83 & $1.39,5.77$ & 2.16 & $0.99,4.70$ \\
\hline 2 partners & 2.49 & $1.19,5.19$ & 2.13 & $0.97,4.70$ \\
\hline 3 or more partners & 3.15 & $1.44,6.89$ & 3.24 & $1.41,7.43$ \\
\hline \multicolumn{5}{|l|}{ History of STIs } \\
\hline No & 1.0 & & 1.0 & \\
\hline Yes & 1.55 & $1.06,2.27$ & 1.48 & $0.99,2.20$ \\
\hline \multicolumn{5}{|l|}{ Tested for HIV } \\
\hline No & 1.0 & & 1.0 & \\
\hline Yes & 1.09 & $0.69,1.72$ & 1.31 & $0.81,2.11$ \\
\hline Newspaper reading & 0.92 & $0.87,0.97$ & 0.96 & $0.91,1.01$ \\
\hline TV viewing & 0.92 & $0.87,0.97$ & 0.92 & $0.87,0.98$ \\
\hline \multicolumn{5}{|l|}{ Internet Use } \\
\hline Never use & 1.0 & & 1.0 & \\
\hline Sometimes use & 0.49 & $0.36,0.68$ & 0.71 & $0.49,1.01$ \\
\hline Often use & 0.47 & $0.35,0.63$ & 0.77 & $0.52,1.14$ \\
\hline
\end{tabular}

AIDS Behav. Author manuscript; available in PMC 2015 February 01. 
${ }^{¥}$ Adjusted for age, gender, education, employment and the other exposure variables in the table. 
Table 4

Bivariate and multivariate ordinal logistic regression models predicting isolation stigma among adults ages 18-61 in Guangxi Province, China

\begin{tabular}{|c|c|c|c|c|}
\hline & \multicolumn{2}{|c|}{$\underline{\text { Bivariate Analyses }}$} & \multicolumn{2}{|c|}{$\underline{\text { Multivariate Analyses }}$} \\
\hline & OR & $95 \% \mathrm{CI}$ & $\mathbf{A O R}^{¥}$ & $95 \% \mathrm{CI}$ \\
\hline \multicolumn{5}{|l|}{ Gender } \\
\hline Female & 1.0 & & 1.0 & \\
\hline Male & 1.02 & $0.80,1.31$ & 1.02 & $0.79,1.34$ \\
\hline Age & 1.02 & $1.01,1.04$ & 1.02 & $1.01,1.04$ \\
\hline \multicolumn{5}{|l|}{ Household Registration } \\
\hline Rural & 1.0 & & 1.0 & \\
\hline Urban & 0.59 & $0.44,0.80$ & 0.66 & $0.46,0.96$ \\
\hline \multicolumn{5}{|l|}{ Education } \\
\hline Less than high school & 1.0 & & 1.0 & \\
\hline High school graduate & 0.56 & $0.43,0.75$ & 0.83 & $0.60,1.14$ \\
\hline Beyond high school & 0.39 & $0.28,0.54$ & 0.84 & $0.55,1.28$ \\
\hline \multicolumn{5}{|l|}{ Employment } \\
\hline Full-time & 1.0 & & 1.0 & \\
\hline Not employed & 1.30 & $0.88,2.16$ & 1.57 & $0.91,2.72$ \\
\hline Retired & 1.43 & $0.97,2.12$ & 0.83 & $0.52,1.33$ \\
\hline Temporary worker & 1.56 & $1.19,2.06$ & 1.18 & $0.88,1.60$ \\
\hline \multicolumn{5}{|l|}{ Transmission knowledge } \\
\hline No knowledge & 1.0 & & 1.0 & \\
\hline Some knowledge & 0.55 & $0.40,0.78$ & 0.63 & $0.44,0.90$ \\
\hline All knowledge & 0.29 & $0.22,0.39$ & 0.38 & $0.28,0.51$ \\
\hline \multicolumn{5}{|c|}{ Number of lifetime sexual partners } \\
\hline None & 1.0 & & 1.0 & \\
\hline 1 partner & 1.38 & $0.75,2.51$ & 0.90 & $0.46,1.77$ \\
\hline 2 partners & 1.56 & $0.83,2.94$ & 1.12 & $0.56,2.22$ \\
\hline 3 or more partners & 1.05 & $0.53,2.09$ & 0.87 & $0.42,1.81$ \\
\hline \multicolumn{5}{|l|}{ History of STIs } \\
\hline No & 1.0 & & 1.0 & \\
\hline Yes & 1.55 & $1.07,2.26$ & 1.65 & $1.11,2.43$ \\
\hline \multicolumn{5}{|l|}{ Tested for HIV } \\
\hline No & 1.0 & & 1.0 & \\
\hline Yes & 0.61 & $0.39,0.96$ & 0.78 & $0.49,1.23$ \\
\hline Newspaper Reading & 0.92 & $0.87,0.96$ & 0.96 & $0.91,1.01$ \\
\hline TV Viewing & 0.95 & $0.90,1.01$ & 0.97 & $0.92,1.02$ \\
\hline \multicolumn{5}{|l|}{ Internet Use } \\
\hline Never use & 1.0 & & 1.0 & \\
\hline Sometimes use & 0.54 & $0.40,0.74$ & 0.83 & $0.59,1.18$ \\
\hline Often use & 0.43 & $0.32,0.57$ & 0.78 & $0.53,1.13$ \\
\hline
\end{tabular}

AIDS Behav. Author manuscript; available in PMC 2015 February 01. 
${ }^{¥}$ Adjusted for age, gender, education, employment and the other exposure variables in the table. 